\title{
Configurações
}

Revista de sociologia

\section{Raewyn Connell e Rebecca Pearse (2015), Gender in World Perspective, 3. edição, Cambridge: Polity Press, $184 \mathrm{pp}$}

\section{Ana Maria Brandão}

\section{(2) OpenEdition \\ Journals}

Edição electrónica

URL: http://journals.openedition.org/configuracoes/2651

DOI: 10.4000/configuracoes.2651

ISSN: 2182-7419

Editora

Centro de Investigação em Ciências Sociais

\section{Edição impressa}

Data de publição: 30 Junho 2015

Paginação: 85-88

ISBN: 1646-5075

ISSN: 1646-5075

\section{Refêrencia eletrónica}

Ana Maria Brandão, « Raewyn Connell e Rebecca Pearse (2015), Gender in World Perspective, 3. ${ }^{\text {a }}$ edição, Cambridge: Polity Press, 184 pp », Configurações [Online], 15| 2015, posto online no dia 01 setembro 2015, consultado o 19 abril 2019. URL : http://journals.openedition.org/configuracoes/2651 ; DOI : 10.4000/configuracoes.2651

Este documento foi criado de forma automática no dia 19 Abril 2019.

(c) CICS 


\title{
Raewyn Connell e Rebecca Pearse (2015), Gender in World Perspective,

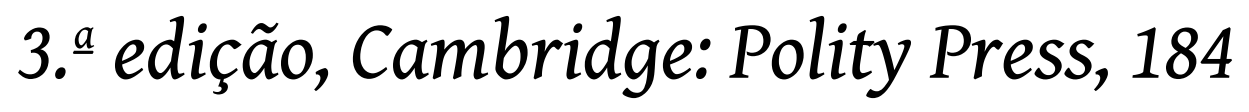 $p p$
}

\author{
Ana Maria Brandão
}

1 Gender in World Perspective, publicado pela primeira vez em 2002, é uma das obras que compõem a coleção Short Introductions da Polity Press. A obra foi escrita, em parceria com Rebecca Pearse, por Raewyn Connell, uma das mais conhecidas e autorizadas sociólogas do género da atualidade. Esta terceira edição é a mais recente atualização da obra, redefinindo articulações presentes nas edições anteriores e acrescentando novas questões à discussão, como é o caso da relação entre género e mudança ambiental, um tema especialmente caro a Rebecca Pearse.

2 Gender in World Perspective encontra-se dividido em oito capítulos. O primeiro capítulo consiste, essencialmente, numa introdução aos conteúdos da obra. Através de exemplos da vida quotidiana, os autores explicam por que razão o que designam de "ordem de género" - um padrão específico de organização da vida social nas suas múltiplas dimensões que tem na base o género - continua a ser um tema atual e relevante. Ao mesmo tempo que sublinham a importância dos "arranjos de género" enquanto fontes de prazer, reconhecimento e identificação, chamam também a atenção para a desigualdade e a injustiça que podem produzir. Recusando uma visão dicotómica e polarizada do género, Connell e Pearse oferecem uma definição abrangente do conceito que sublinha a sua contínua (re)produção através da ação de estruturas e relações particulares e que é aprofundada nos capítulos subsequentes.

3 No capítulo 2, são discutidas cinco investigações provenientes dos cinco continentes, que ilustram algumas das principais preocupações deste domínio de estudo: a dimensão situacional do género, ilustrada num estudo sobre as brincadeiras das crianças norteamericanas em contexto escolar; o efeito determinante da estrutura social, em particular 
da economia e da política, sobre os entendimentos da masculinidade entre os mineiros da África do Sul; a complexa interação entre género e sexualidade, que ultrapassa os limites e a rigidez das categorias dominantes, exemplarmente ilustrada num estudo acerca do impacto da sida nas práticas e identidades sexuais e de género em redes homossexuais de comunidades operárias australianas; os efeitos dos significados culturais do género sobre as experiências individuais a partir da análise cultural das memórias de guerra de mulheres, que desoculta as dinâmicas escondidas pelo discurso e pelas políticas soviéticas de promoção da igualdade e o modo como têm contribuído, de modo aparentemente paradoxal, para sustentar a deriva patriarcal que se seguiu ao colapso da URSS; a presença da agência, que sustenta a possibilidade de mudança a partir da ação - individual e coletiva - ilustrada na análise da relação entre género, política e ambiente numa comunidade local marginalizada do Bornéu indonésio e dos impactos do ecofeminismo no movimento ambientalista indonésio do final da década de 1990.

Os capítulos 3 e 4 prosseguem de uma visão crítica do género para a história da sua conceptualização. No capítulo 3, convocando estudos de diferentes áreas disciplinares, incluindo a genética e a biologia, os autores discutem e rebatem as teses - comuns e eruditas - que defendem, ou se esforçam por encontrar, "diferenças de género" radicadas nos mecanismos de reprodução, no corpo sexuado e/ou em qualquer modelo de análise dimorfo. Connell e Pearse apresentam uma demonstração sistemática e empiricamente robusta das similaridades de género e desafiam-nos a equacionar de forma não dicotómica e não hierárquica a relação entre corpo, sociedade e género. Para tal, avançam com a noção de "incorporação social" para se referirem ao processo histórico através do qual os corpos se constituem, simultaneamente, como objetos da e agentes na prática social. O género é uma forma específica de incorporação social e um sistema histórico de relações. A questão não é, então, a de saber se os arranjos de género podem mudar, mas de que forma e em que sentido estão a mudar. No capítulo 4, é traçada uma sinopse das teorias do género em articulação com as condições materiais e teóricas da sua produção. Connell e Pearse explicitam as origens históricas do pensamento ocidental acerca do género, mas também o modo como este tem sido apropriado, contestado e modificado. Num exercício abrangente de proficiência e virtuosismo, o leitor é conduzido, em cerca de vinte páginas, das preocupações germinais e mais pragmáticas com as desigualdades de género em diversas partes do mundo às mais recentes abordagens queer, pós- colonialistas, do Sul e globais. Esta é, provavelmente, a secção mais complexa de Gender in World Perspective pela multiplicidade de temas e abordagens que convoca, assim como pelo desafio que levanta à capacidade de o leitor se descentrar da sua mundividência particular, mas que faz jus à intenção de situar a discussão no plano global/mundial.

o capítulo 5 trata das relações e da "política de género" a partir de três conceitos fundamentais: os "regimes de género", que se referem aos arranjos de género característicos de uma instituição, organização ou agência; a "ordem de género", que se refere aos padrões mais vastos e persistentes do género que enquadram esses regimes e funcionam como modelos para a ação; e o conjunto das relações na base desses regimes e dessa ordem, habitualmente designado de "relações de género", continuamente (re)produzido na interação. Partindo destas noções, os autores propõem um modelo heurístico de análise da estrutura de género assente em quatro dimensões interligadas: poder, produção, catexia e simbolismo. Estas quatro dimensões influenciam-se e apoiamse mutuamente, e são ainda influenciadas por outras estruturas sociais, como a classe. Mostrando, através de vários exemplos, como os regimes e ordens de género assumem um 
carácter estrutural e estruturante das relações de género, Connell e Pearse debatem, igualmente, as condições da mudança. Para tal, baseiam-se na noção de "tendências de crise", que se refere à presença, no seio da própria estrutura de género, de contradições internas cumulativas que debilitam os padrões existentes e forçam a mudança estrutural. Trata-se de uma abordagem inspirada no pensamento de Jürgen Habermas, que permite dar conta quer dos períodos em que as pressões para a mudança se acumulam gradualmente, quer daqueles em que dão origem a crises e forçam a mudanças rápidas, identificando, simultaneamente, as forças que a impulsionam e as que lhe resistem.

Definidos os marcos conceptuais fundamentais, os três capítulos seguintes aprofundam os mecanismos, impactos e implicações da "política de género" - mas também da "política da identidade" - em três domínios distintos: género e vida pessoal; género e mudança ambiental; e economias, Estados e relações globais de género, respetivamente.

7 O capítulo 6 ilustra o modo como as relações pessoais e íntimas são influenciadas pelas instituições, economias, ideologias e governos. Criticando o monolitismo e a unidimensionalidade do que designam de "teoria da socialização de género", os autores propõem, em alternativa, um modelo explicativo assente na ideia de que o género é o resultado de uma aprendizagem incorporada e ativa, pejada de contradições e desafios, que se traduz na existência de diferentes "trajetórias de formação" influenciadas pelas "configurações de género" existentes em cada momento, mas também resultado de "projetos de género" particulares. Essas trajetórias são atravessadas por desigualdades de classe, pela diversidade étnica, por diferenças regionais e nacionais, entre outros fatores. Sendo o género um fundamento da identidade, ele não é, portanto, um simples decalque de modelos normativos, mas o resultado de um processo e um alvo de disputa - inclusive política - que muda com as condições da sua (re)produção. A última seç̧ão do capítulo lida, precisamente, com o exemplo mais paradigmático da influência das relações sociais nos processos de formação do género, que é também uma negação do realismo biológico: o caso das pessoas transgénero e transexuais.

O capítulo 7 trata da relação entre género e ambiente e do modo como tem sido equacionada pelo pensamento feminista a relação entre género e Natureza. Partindo de uma revisão crítica das correntes ecofeministas e ambientalistas feministas e do debate em torno da questão da "natureza das mulheres", os autores equacionam questões como o desenvolvimento, a sustentabilidade e a justiça ambiental e debatem a especial vulnerabilidade das mulheres aos efeitos das alterações climáticas e aos riscos ambientais - mas também o papel fundamental que podem ter na sua inversão - devido à sua sobrerrepresentação entre os mais pobres, ao seu papel de cuidadoras e à sua forte presença no trabalho agrícola.

9 No capítulo 8, são discutidos os impactos da globalização da vida social nas relações de género. A empresa capitalista, motor da globalização, tem sido gerida segundo uma lógica "masculina" de competitividade, mobilidade e centralidade do trabalho cuja crescente sofisticação oculta frequentemente a presença do "dividendo patriarcal", isto é, de vantagens que os homens enquanto grupo retiram da sua posição dominante em termos de rendimento, reconhecimento, poder, apoio emocional, prazer sexual e autodeterminação. Ela é o modelo emulado por outras organizações formais, como os sindicatos, mas também pelos próprios Estados e pelas suas agências, onde idêntico efeito pode ser observado. Com o processo de globalização, esses processos e os seus efeitos ultrapassam as fronteiras dos Estados, traduzem-se na interação entre as ordens locais de género e uma nova arena global e situam as discussões acerca da política de género no 
plano transnacional de que as iniciativas de mainstreaming de género são exemplo. Os obstáculos, porém, continuam a ser muitos, e vão da suborçamentação destas políticas às ameaças das políticas neoliberais. 0 que está hoje em jogo, argumentam os autores, é uma democratização do género que permita preservar os seus aspetos positivos e caminhar no sentido da igualdade e da justiça.

Apesar do carácter enciclopédico de Gender in World Perspective, a utilização de uma linguagem simples, a lógica de exposição clara e o recurso constante a exemplos diversificados e atuais fazem da obra uma interessante primeira abordagem às questões do género e ao modo como este se cruza com várias dimensões da vida social, constituindo um excelente ponto de partida para estudantes, investigadores e público em geral interessados em aprofundar os seus conhecimentos neste domínio. Sobretudo, Connell e Pearse mostram como uma questão considerada, muitas vezes, "menor" constitui uma dimensão fundamental da vida social cuja desconsideração pode apenas ter como resultado uma democracia anquilosada e incompleta.

\section{AUTHOR}

\section{ANA MARIA BRANDÃO}

Prof. Auxiliar do Departamento de Sociologia do Instituto de Ciências Sociais da Universidade do Minho e Investigadora Integrada do Centro Interdisciplinar de Ciências Sociais - Polo UMinho (CICS.NOVA.UMinho). Endereço de correspondência: CICS.NOVA.UMinho Campus de Gualtar, 4710-057 Braga

anabrandao@ics.uminho.pt 